\title{
Simposio \\ Modelos MATEMÁticos de LAS \\ ENFERMEDADES PARASITARIAS
}

\section{A mathematical model approach to understand the dynamics of Chagas disease in Colombia}

\author{
Diana Erazo, Juan M. Cordovez \\ Departamento de Ingeniería Civil y Ambiental, Universidad de los Andes, Bogotá, D.C., Colombia
}

\section{Introduction}

Chagas' disease is caused by the parasite Trypanosoma cruzi and is transmitted to humans by insects of the family reduviidae. It is a major public health problem in Latin America and recent estimates suggest 8 million people infected and 10,000 deaths per year (1). The disease has different ecological and clinical manifestations that correlate to different geographical locations. Thus, in the southernmost part of the continent Triatoma infestants, a highly domiciliated insect, is the main vector of the disease and visceral complications are observed in chagasic patients (2). In Colombia, the main vector is Rhodnius prolixus, associated with palm trees, and heart tissue damage is the most common clinical manifestation in humans (2).

Current disease eradication efforts include people awareness, test for T. cruzi in blood transfusion and house spraying programs. In Colombia, however, insecticides are of limited usefulness because of a strong house reinfestation phenomena supported by sylvatic populations of $R$. prolixus. During the years 2006-2007 a local Chagas prevention program identified several villages in the Casanare region of Colombia were active parasite transmission is observed (3). House spraying was implemented but a few months later high re-infestation indices were reported. Thus, different control strategies are required to diminish incidence of Chagas disease in Colombia.

Even though the spraying was not sufficient to stop house infestation, several important epidemiological questions arose from these studies. For example, what is the time frame for house re-infestation? Are the domiciliated insects creating colonies inside the houses or do incoming sylvatic insects actively replace them? What are the densities observed and how they correlate to house characteristics, such as construction materials, number of people, presence of domestic animals and location relative to palm trees?

Currently we do not have enough data to answer these questions, but we know a lot about biological and ecological characteristics of $R$. prolixus that can help us to better understand the re-infestation phenomena and characterize the dynamics of the disease.

Here, we investigate the infestation of houses from a theoretical perspective, similar to other approaches (4), using a computer model that simulates insect dispersal with parameters derived both from published papers and surveys taken during a control program in Colombia (5). In particular, we tested the effect of palm density and distance between houses and palms, in house infestation, infestation densities and proportion of insects inside houses that come from a sylvatic origin.

\section{Methods}

We implemented a stochastic dispersal model to study $R$. prolixus house infestation dynamics in a hypothetical village. The model was implemented in Matlab® (6) and had a spatial component set by the characteristics of the village and a time component that involved hourly increments up to one year.

We simulated population dynamics and dispersal behavior at the individual level using an approach that followed three steps. First, we generated a $4 \mathrm{~m}$ pixel (cell) raster map with the spatial configuration of the villages in terms of location of palms and houses, other areas were not considered relevant for insect dispersal and settlement, we also assumed an initial insect density distribution in the village. Second, we considered vector population dynamics by introducing an age dependent survival rate (7) and a reproductive rate that was a function of female age (8), average number of eggs laid 
per female (8), inter-mate interval (9) and male abundance. Third, we assumed that the insects would disperse in the grid based on environmental quality factors. Thus, at every time step all the insects that were older than a minimum dispersal age (10) were considered for movement. In this way, a set of cells in a radius (derived for dispersal studies (11) and generated using a probability function) surrounding the current position of the insect was activated as targets for movement.

The quality of these cells was compared to the current cell and movement would occur only if there was a cell with higher quality than the current one inside the set of target cells. Cell quality is related to how attractive is a location for an average insect and depends on several factors. For a cell that corresponds to a house, quality is determined by house building materials (i.e., houses made out of palm leaves, cracked walls give higher quality), number of people living in the house, number of domestic animal species present in the house. All these factors were set randomly at the beginning of the simulation and remained constant.

On the other hand, house infestation levels (number of insects inside the house at every time step), was variable during the simulation, which along with the aforementioned parameters was used for the computation of house quality for every time step.

The overall house quality was a number that changed in a holing type of effect, that is, there is a combination of factors that provides optimal attractiveness but combinations above and below that number reduce quality in a nonlinear way. Similarly, a cell that corresponds to palm trees had also a density dependent quality but we did not consider palms characteristics, such as height, location and number of leaves as factors to compute quality. Quality was normalized across the entire grid so maximum quality was set equal to 1 and minimum quality equal to 0 .

\section{Results}

We simulated dispersal dynamics in three hypothetical villages. All the simulations lasted for
8,000 hours (approximately 1 year) with a 1 -hour time step. We characterize each village in terms of number of palms, number of houses, initial number of insects and average distance between houses and palms, taken as the mean of all the distances between every house and every palm. We kept house characteristics constant for all three villages.

For construction materials we used 6, (being 3 very unattractive for insect colonization and 9 very attractive), people densities was 5 persons per house and the average number of domiciliated species was set as 2 per house.

For every simulation we found the average proportion of sylvatic insects inside houses (computed continuously and averaged for the entire simulation), infestation and density index (computed as number of infested houses divided by the total number of houses and the number of insects per infested house at the end of the simulation respectively).

The table summarizes our findings. We found that higher palm densities suggest high infestation index but lower density index, which in turn increases with decreased house to palm distance. Interestingly, the average proportion of insects with sylvatic origin inside the houses remains relatively constant.

\section{Conclusions}

We believe that the spatially (landscape configuration) dependent house infestation patterns observed with the model suggest control programs that include this information to optimize efficacy. In particular palm abundance, but coordinated with house distribution, seem to be important for infestation patterns.

We believe that factors such as presence of domestic animals, human densities and house materials should also provide strong clues about insect density levels, we plan to test these hypothesis in future experiments.

The time it takes for an insect to arrive to a given house depends on insect density, house distance to palms and house quality.

We are currently developing fieldwork to validate

\begin{tabular}{lccccccc}
\hline Village & $\begin{array}{c}\text { Number } \\
\text { of palms }\end{array}$ & $\begin{array}{c}\text { Number } \\
\text { of houses }\end{array}$ & $\begin{array}{c}\text { Initial } \\
\text { number } \\
\text { of } \\
\text { insects }\end{array}$ & $\begin{array}{c}\text { Distance } \\
\text { between } \\
\text { houses } \\
\text { and palms }\end{array}$ & $\begin{array}{c}\text { Insects with } \\
\text { sylvatic } \\
\text { origin inside } \\
\text { the houses }\end{array}$ & $\begin{array}{c}\text { Infestation } \\
\text { index }\end{array}$ & $\begin{array}{c}\text { Density } \\
\text { index }\end{array}$ \\
\hline 1 & 194 & 49 & 970 & 38.46 & 0.74 & 0.10 & 58.8 \\
2 & 194 & 49 & 970 & 43.73 & 0.70 & 0.31 & 12.33 \\
3 & 291 & 49 & 1455 & 37.24 & 0.71 & 0.59 & 10.14 \\
\hline
\end{tabular}


our model using real villages and improve our understanding of insect dispersal and house infestation.

\section{References}

1. Organización Mundial de la Salud. Enfermedad de Chagas: control y eliminación. Ginebra: OMS; 2010

2. World Health Organization. Control of Chagas Disease. Second Report of the WHO Committee. WHO Technical Report Series 905. Geneve: WHO; 2002.

3. Guhl F. Enfermedad de Chagas: ¿Son realmente útiles las estrategias de control y prevención? Estado actual ¿Qué se debe hacer? En: Cabrales M, editor. Enfermedad de Chagas. Bogotá: Sociedad Colombiana de Cardiología y Cirugía Cardiovascular; 2007. p. 187-96.

4. Barbu C, Dumonteil E, Gourbiere S. Characterization of the dispersal of non-domicialiated Triatoma dimidiata through the selection of spatially explicit models. PLoS 2010;4:e777.

5. Guhl F. Estado del arte de la enfermedad de Chagas en Colombia y estrategias de control. En: Guhl F, Davies C, editores. Bogotá: Universidad de los Andes; 2006. p. 152-61

6. Matlab®. The MathWorks Inc., Massachusets, 19842011.

7. Chaves LF, Hernández MJ, Revilla TA, Rodríguez DJ, Rabinovich JE. Mortality profiles of Rhodnius prolixus (Heteroptera: Reduviidae), vector of Chagas disease. Acta Trop 2004;92:119-25.

8. Arévalo A, Carranza JC, Guhl F, Clavijo JA, Vallejo GA. Comparación del ciclo de vida de Rhodniuscolombiensis. Biomédica. 2007;27:119-29.

9. Gómez-Núnez JC. Mass rearing of Rhodnius prolixus. Bull World Health Organ. 1964;31:565-7.

10. Rabinovich JE, Himschoot P. A population dynamics simulation model of the main vectors of Chagas' Disease transmission, Rhodnius prolixus and Triatoma infestans. Ecol Model. 1990;52:249-66.

11. Gómez-Núnez JC. Resting places, dispersal and survival of CO60-tagged adult Rhodnius prolixus. J Med Entomol. 1969;6:83-6.

\section{Modeling cutaneous leishmaniasis transmission in Costa Rica}

Luis Fernando Chaves

Hokkaido University, Sapporo, Japan

American cutaneous leishmaniasis is one of the most important emerging and re-emerging neglected tropical diseases in the New World. Like many other vector-borne diseases, there is a growing concern about the impact of global climate change on its dynamics and spatial distribution. Cutaneous leishmaniasis is also of special interest because of its diverse array of hosts. American cutaneous leishmaniasis emergence has been directly or indirectly linked to changes in species diversity.

Here, I will present results from a series of studies on American cutaneous leishmaniasis in Costa Rica dealing with the internal relations of the disease with climatic variability and biodiversity changes.

First, I will show a series of analyses describing the connections between the disease and global climate phenomena like EI Niño Southern Oscillation (ENSO). The coupling between the disease and climate was strong enough to improve the accuracy of forecasts about future incidence for the whole country (Chaves and Pascual, 2006, 2007). A more detailed ecological analysis of American cutaneous leishmaniasis temporal dynamics supported a mechanism where infections develop with a delay after exposure (Chaves, 2009). At a more finely grained spatial scale (counties) the spatial determinants of the disease seemed to be related with social exclusion and deforestation. The largest burden of the disease was concentrated in the most socially excluded counties in southern Costa Rica, with clear increases in incidence following the ENSO in the more heavily deforested areas (Chaves, et al., 2008).

Second, I will present a series of results on the relationship of the disease with biodiversity. I will begin by describing patterns of sand fly species co-occurrence across altitudinal and ecosystem gradients (Chaves and Añez, 2004) and in agricultural and forest landscapes (Chaves, 2011). These studies showed that sand flies segregate across altitude and vegetation units, and that homogeneous transformed landscapes promote the dominance of selected vector species. I will also show results from mathematical models used to better understand the influence that reservoir and incidental hosts have on disease dynamics (Chaves and Hernández, 2004, 2006; Chaves, et al., 2007). These models showed that changes on the endemic equilibrium of American cutaneous leishmaniasis are only sensitive to changes in reservoirs species, and that, assuming a homogeneous host species 
use, biodiversity decreases the likelihood of disease establishment.

Finally, I will describe ongoing research looking at the connection between climatic variability, land use change and vector and reservoir diversity on the spatial distribution of American cutaneous leishmaniasis in southern Costa Rica.

\section{References}

1. Chaves LF, Añez N. Species co-occurrence and feeding behavior in sand fly transmission of American cutaneous leishmaniasis in western Venezuela. Acta Trop. 2004;92:219-24.

2. Chaves LF, Hernández MJ. Mathematical modelling of American cutaneous leishmaniasis: incidental hosts and threshold conditions for infection persistence. Acta Trop. 2004;92:245-52.

3. Chaves LF, Pascual M. Climate cycles and forecasts of cutaneous leishmaniasis, a non-stationary vectorborne disease. PLos Med. 2006;3:1320-8.

4. Chaves LF, Hernández MJ. Modelos matemáticos y dinámica de transmisión de la leishmaniasis cutánea americana. En: Scorza JV, Rojas E, editores. Voces para sordos. Mérida, Venezuela: Universidad de Los Andes; 2006. p. 33-46.

5. Chaves LF, Pascual M. Comparing models for early warning systems of neglected tropical diseases. PLoS Negl Trop Dis. 2007;1:e33.

6. Chaves LF, Hernández MJ, Dobson AP, Pascual M. Sources and sinks: revisiting the criteria for identifying reservoirs for American cutaneous leishmaniasis. Trends Parasitol. 2007;23:311-6.

7. Chaves LF, Cohen JM, Pascual M, Wilson ML. Social exclusion modifies climate and deforestation impacts on a vector-borne disease. PLoS Negl Trop Dis. 2008;2:e176.

8. Chaves LF. Climate and recruitment limitation of hosts: the dynamics of American cutaneous leishmaniasis seen through semi-mechanistic seasonal models. Ann Trop Med Parasitol. 2009;103:221-34.

9. Chaves LF. Sand fly species co-occurrence at the local scale: Differences between agricultural and forested areas. Boletín de Malariología y Salud Ambiental. 2011;51; en prensa.

\section{Experience in the implementation of malaria dynamical models in the pilot sites of the Integrated National Adaptation Pilot project}

Daniel Ruiz ${ }^{1,2,3}$, Viviana Cerón ${ }^{4}$, Madeleine Thomson², Stephen Connor ${ }^{2}$, Adriana María Molina', Martha Lucía Quiñones ${ }^{5}$, Mónica Marcela Jiménez ${ }^{6}$, Martha Ahumada ${ }^{4}$, Patricia Gutiérrez ${ }^{4}$,

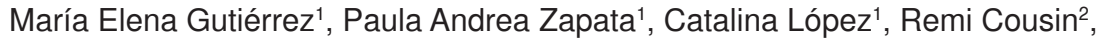
Salua Osorio ${ }^{4}$, Gilma Mantilla ${ }^{2}$

${ }^{1}$ Grupo de Investigación ‘Gestión del Ambiente para el Bienestar Social', Escuela de Ingeniería de Antioquia, Medellín, Colombia

2 International Research Institute for Climate and Society, Columbia University, New York, NY, USA

${ }^{3}$ Department of Earth and Environmental Sciences, Columbia University, New York, NY, USA

${ }^{4}$ Subdirección de Vigilancia y Control en Salud Pública, Instituto Nacional de Salud, Bogotá, D.C., Colombia

${ }^{5}$ Facultad de Medicina, Universidad Nacional de Colombia, Bogotá, D.C., Colombia

${ }^{6}$ Instituto Colombiano de Medicina Tropical, Universidad CES, Sabaneta, Colombia

As part of the Integrated National Adaptation Plan, the Colombian National Institute of Health is working on the implementation of a proactive, collaborative, multidisciplinary, integrated surveillance and control system. The aim of this initiative is to improve risk assessments of malaria transmission in order to facilitate effective allocation of health resources and more cost-effective preventive responses.

One of its key components is an early warning system framework, in which the Colombian National Institute of Health is proposing several dynamical and statistical models. Dynamical models, in particular, are being used to integrate climatic variables with non-climatic factors in order to simulate malaria transmission dynamics. Twelve process-based models and one tool for decision makers were studied and included in a single multi-model platform. Four of those models were merged in an executive version of the multi-model ensemble.

This talk will socialize our experience in the implementation of the selected malaria dynamical models in four Colombian pilot sites with different eco-epidemiological settings. In the first part we will discuss the main hypothesis, present an overview of data and methods, and describe the main local characteristics of malaria infections, such as the predominant type of infection and level of endemicity, general profiles (populations at risk, natural resources and economic activities), climatic conditions (seasonality, long-term trends), entomological conditions (primary and secondary 
vectors, mosquito density, breeding sites, feeding frequencies, and mosquitoes' blood preference), annual cycles of malaria incidence and inferred stability of malaria transmission, key drivers of epidemic outbreaks, and key non-climatic factors (including malaria control interventions and campaigns).

In the second part we will discuss the results of retrospective simulation experiments (base scenarios, changes in initial conditions, local settings, sensitivity analyses, and uncertainties) of at least 8-year simulation periods.

The third part will consist of a short description of the activities that were conducted to integrate short-, medium- and long-term climate predictions into simulations of future changing scenarios.

The last part will deal with complementary and outreach activities conducted during our research. Complementary activities included the study of local spatial patterns of vectorial capacity, descriptions of the vulnerability of populations at risk, and a conceptual framework for the analysis of non-climatic drivers. Outreach activities included the design of interactive and online platforms, the implementation of environment-informed systems at local levels, and the documentation of our experiences. Dynamical models have improved our understanding of malaria complexity, allowed us to estimate previous malaria outbreaks in the selected pilot sites, and helped us to investigate decision-making processes.

\section{References}

1. Chaves LF, Koenraadt CJM. Climate change and highland malaria: fresh air for a hot debate. $Q$ Rev Biol. 2010;85(1).

2. Chitnis N, Schapira A, Smith D, Hay S, Smith T, Steketee R. Mathematical modelling to support malaria control and elimination. Roll Back Malaria, Progress and Impact Series, No. 5. November 2010

3. Poveda G, Rojas W, Quiñones ML, Vélez ID, Mantilla RI, Ruiz D, Zuluaga JS, Rúa GL. Coupling between annual and ENSO scales in the malaria-climate association in Colombia. Environ Health Perspect. 2001;109:489-93.

4. Reiter P. Global warming and malaria: knowing the horse before hitching the cart. Malar $\mathrm{J}$. 2008;7(Suppl.1):S3.

5. Ruiz D, Connor S, Thomson M. A multimodel framework in support of malaria surveillance and control. In: Thomson MC, García R, Beniston M, editors. Seasonal forecasts, climatic change, and human health. Health and climate / advances in global change research. Dordrecht: Springer Netherlands; 2008. p. 101-25.

6. Ruiz D, Poveda G, Vélez ID, Quiñones ML, Rúa GL, Velásquez LE, Zuluaga JS. Modelling entomologicalclimatic interactions of Plasmodium falciparum malaria transmission in two Colombian endemicregions: contributions to a national malaria early warning system. Malar J. 2006;5:66.

\title{
Dynamic perspectives on epidemic malaria and climate forcing
}

\author{
Mercedes Pascual \\ University of Michigan and Howard Hughes Medical Institute, Ann Arbor, MI, USA
}

\section{Background}

Despite the clear role of climate variables, temperature and rainfall, in the life cycle of mosquito vectors and in the development of malaria parasites, the influence of both climate variability and climate change in the temporal patterns of the disease remains controversial, largely because of the relative role of climate forcing vs. control. These temporal patterns include differences in disease burden from year to year (interannual variability), and longer-term trends over decades.

\section{Approach}

Here, we focus on epidemic or 'unstable' malaria in highland and desert fringes, at the edge of the distribution of the disease where temperature and rainfall respectively act as limiting factors on disease transmission. The transition to more endemic regimes is also considered. Mathematical models of transmission that combine epidemiological dynamics and climate variables are confronted to temporal incidence records to address hypotheses on the role of climate forcing.

\section{Highland malaria and climate change}

Evidence is presented for a role of warming trends in the exacerbation of malaria in recent decades in an East African highland. The transmission model illustrates the nonlinear response of incidence with increasing temperatures, which can occur as a regime shift between two different equilibrium levels (Alonso, et al., 2010).

\section{Desert malaria and climate variability}

The relevance of thresholds in the response to climate forcing is also apparent in the dynamics of epidemic malaria in arid and semi-arid regions of 
NW India (Laneri, et al., 2010). Rainfall acts as a key driver of interannual malaria variability in both Plasmodium falciparum and Plasmodium vivax malaria, which allows the identification of predictive thresholds in both a remote sensing measure of vegetation and an index of sea surface temperature anomalies in the Atlantic associated with monsoon intensity. Changes in the coupling of malaria cases to climate forcing are apparent along a land-use gradient of irrigation, at the same time that disease risk itself remains under the influence of rainfall levels (Baeza, et al., in press). These patterns most likely reflect more effective control measures in the more affluent districts.
We discuss the implications for the interaction of reactive control and climate forcing, in particular the possibility of unexpected large epidemics.

\section{References}

1. Alonso D, Bouma M, Pascual M. Epidemic malaria and warmer temperatures in recent decades in an East African highland. Proc Biol Sci. 2011;278:1661-9.

2. Baeza A, Bouma MJ, Dobson A, Dhiman RC, Srivastava $\mathrm{H}$, Pascual M. Climate forcing and desert malaria: the effect of irrigation. Malar J. 2011, in press.

3. Laneri K, Bhadra A, lonides E, Bouma MJ, Dhiman R, Yadav R, Pascual M. Forcing vs. feedback: epidemic malaria and monsoon rains in NW India. Plos Compt Biol 2010;6:e1000898. 